\title{
Fitstorias
}

(PPGHIS/UnB) №. 31, Brasília, Ago - Dez 2017 ISSN 2316-1191

Recebido: $27 / 08 / 2017$

Aprovado: 10/12/2017

\section{Simpatia, alteridade e compreensão no ofício do historiador}

Rodrigo Nunes do Nascimento*

Resumo: A partir da análise do uso do conceito de epokhé e simpatia (sympathie) por HenriIrénée Marrou em "De la connaissance historique" (Do conhecimento histórico), a intenção deste artigo é entender a necessidade da simpatia e da alteridade na abordagem das fontes e do passado pelo historiador como um dos requisitos fundamentais para o alcance da compreensão (Verstehen) e do conhecimento históricos.

Palavras-chave: Epokhé; Alteridade; Compreensão Histórica

Abstract: Investigating the use of the concept of epokhéand empathy (sympathie) by HenriIrénée Marrou in "De la connaissance historique" (On historical knowledge), this article aims to understand the need for empathy and alterity to an approach of the sources and the past by the historian as one of the most essential requisites to achieve comprehension (Verstehen) and historical knowledge.

Keywords: Epokhé; Alterity; Historical Comprehension

\footnotetext{
* Mestrando em História pela Universidade de Brasília, e-mail: rodrigo.nunes90@gmail.com
} 
Com efeito, para o homem, enquanto homem, nada tem valor a menos que ele possa fazê-lo com paixão.

Max Weber, Ciência e Política: duas vocações.

Desde a virada do século XIX para o XX tem sido notável a crescente especialização das ciências. Nas chamadas ciências humanas não é e não foi diferente. Max Weber (1864 1920), como testemunha de seu tempo, percebeu que a ciência atingia um estágio de especialização jamais visto e que tal fenômeno seria irreversível (2000:26). Segundo Weber, “jamais um indivíduo poderá ter a certeza de alcançar qualquer coisa de valor verdadeiro no domínio da ciência, sem possuir uma rigorosa especialização" (2000:26) e para alertar os amadores: "em nosso tempo, obra verdadeiramente definitiva e importante é sempre obra de especialista" (2000:27). No entanto, o próprio Weber adiciona um elemento que nem sempre é levado em conta, ou pelo menos não frequentemente refletido, no domínio científico: a paixão, que é um "requisito da inspiração". A especialização por si só não produzirá algo que "encerre valor", é necessário paixão, inspiração, um fator decisivo, e intuição (2000:28-29).

Não cabe aqui o imenso debate sobre o estatuto científico da história. Os objetivos são outros, bem diferentes. Porém, vale a pena mencionar que nos contextos desses estágios de especialização se realizaram constantes tentativas de atribuir status científico à história desde sua constituição como disciplina especializada no século XIX. Como exemplo pode-se citar o debate entre Claude Lévi-Strauss e Fernand Braudel acerca da natureza da história. Enquanto Lévi-Strauss argumentava em seu texto "História e Etnologia" (1995) de 1949 (reeditado em 1958) que a história não se constituiria como ciência pela ênfase, de uma postura tradicional, apenas nos acontecimentos e em seu tempo curto, Braudel replicou apresentando o trabalho que já estava sendo feito com as estruturas e o tempo de longa duração, dentre outros (RODRIGUES, 2009:165-186).

No século XXI o que se ver é uma explosão de métodos, técnicas e paradigmas para a história. Parece até antiquado propor uma reflexão sobre simpatia e alteridade na prática do historiador. Mas como veremos, a reflexão pode mesmo ir além considerando também a amizade e o amor, conceitos que de primeira vista não parecem estar relacionados ao conhecimento histórico e ao fazer historiográfico. Todos esses conceitos e sentimentos, no entanto, são essenciais para a compreensão histórica (das Verstehen), que por sua vez, é essencial à elaboração do conhecimento histórico (MARROU, 1974:75). 
Assim, a proposta deste artigo é em um primeiro momento analisar como o conceito de epokhé (suspensão do juízo), tomado emprestado da fenomenologia contemporânea por Marrou, é construído ao longo de seu clássico livro De la connaissance historique (Do conhecimento histórico). É mediante a epokhé que o historiador pode sair de si para avançar ao encontro do outro. Essa disposição é considerada como uma virtude por Marrou que a chama de simpatia, "sympathie" (1974:87). O conceito de epokhé e simpatia quase se confundem, mas é preciso perceber que é a epokhé que conduz a uma relação de simpatia e alteridade com os documentos históricos e os homens do passado.

Daí temos uma problemática e um entrelaçamento entre esses conceitos que envolvem vários aspectos metodológicos e teóricos próprios do ofício do historiador. Essa problemática será desenvolvida em um segundo momento, onde serão destacados as potencialidades e os limites da simpatia, alteridade e compreensão histórica. Por meio da epokhé estabelece-se a relação de simpatia e alteridade entre o historiador e o que lhe é diferente, estranho e distante e ao mesmo tempo ao que lhe pode ser semelhante, familiar e por vezes próximas. Simpatia e alteridade, assim como em uma relação de amizade, são necessárias para a compreensão do outro, e o conhecimento histórico somente é possível através dessa compreensão.

\section{A suspensão do juízo em Marrou}

O conceito de epokhé, do grego $\varepsilon \pi o \chi \eta$ (na tradição alemã Ausschaltung), possui uma extensa tradição que remonta à antiguidade com os estoicos e os céticos gregos. $\mathrm{O}$ ceticismo o concebia como um estado psicológico (LENNON, 2011: 37-62). Fundado por Pirro de Élida (360-270 a.C.), o ceticismo antigo negava a possibilidade de se conhecer a verdade. Desse modo, a postura do sábio diante de uma dada questão ou proposição é suspender o juízo (epokhé), dado que não existe um critério decisivo, já que na busca de uma mesma verdade há diferentes posições que se excluem. Tal postura, a da epokhé, seria um estado mental que conduz a ausência de sensações (apathia), a ausência de discurso (aphasia), onde não se pode negar ou afirmar nada, e finalmente ao estado de tranquilidade e imperturbabilidade (ataraxia) que permite o alcance da felicidade (eudaimonia), (MARCONDES, 2001:93-100).

Pelo que já vimos na introdução sobre o uso da epokhé em Marrou, fica claro que a noção assumiu outro significado ao longo do tempo. Aqui será considerada a carga de significado, ligeiramente diferente da do ceticismo pirrônico, que o termo tomou na 
fenomenologia contemporânea, principalmente em Husserl. Marrou considera que há uma contribuição da fenomenologia que não pode ser desprezada, devido suas questões sobre a elaboração do conhecimento histórico e o sentido da história (1974:18). O empréstimo da noção de epokhé, no entanto, não pode ser feito sem as transposições necessárias. A noção é aplicada ao eu, "às suas preocupações, àquilo a que eu chamava a urgência existencial - não como Husserl ao mundo natural" (1974:80).

Do conhecimento histórico é um livro impregnado de tradições filosóficas. Marrou traça e descreve sua própria genealogia filosófica onde inclui Bergson, neokantianos, neohegelianos, Husserl, existencialistas e Raymond Aron (TOPOLSKI, 1976:146-147, 1974:723). De acordo com Topolski, a "armadura antipositivista" desse livro é formada pela seleção de teorias gnoseológicas dessas tradições. A categoria fenomenológica de epokhé de Husserl exerce o papel central, porém, Topolski dirige uma crítica a Marrou dizendo que o mesmo vulgarizou a categoria, "a qual pretendia significar uma sui generis suspensão da abordagem de alguém ao mundo objetivo, libertando o mesmo de convicções no processo cognitivo" (1976:147).

Para uma definição concisa e didática do que significa a epokhé em Husserl é útil se recorrer ao dicionário. A finalidade da epokhé é "a contemplação desinteressada, ou seja, uma atitude desvinculada de qualquer interesse natural ou psicológico na existência das coisas do mundo ou do próprio mundo na sua totalidade" (ABBAGNANO, 2007). Segundo Husserl, a suspensão do juízo coloca o mundo "entre parênteses" (MARCONDES, 2001:258). Aplicando essa noção ao "eu" e considerando a alteridade, Marrou conclui que "o encontro de outrem supõe, exige que 'ponhamos em suspenso', coloquemos entre parênteses, esqueçamos por momentos o que somos para nos abrirmos sobre esse outrem" (1974:80). Daí surge a ideia de simpatia, a identificação gradual da personalidade do historiador com a do objeto, da pessoa estudada, que no pensamento de Marrou é o principal meio intuitivo de cognição (Cf. TOPOLSKI, 1976:147).

A atitude da epokhé, e por consequência, da simpatia, requer que a "exacerbação do espírito crítico" seja deixada de lado. Para Marrou essa é uma reviravolta na perspectiva, pois para os "mestres positivistas", o espírito crítico era considerado a mais importante virtude do historiador (1974:87). Relacionando a noção de epokhé à compreensão dos documentos pelo historiador temos que 
(...) a atitude de submissão ao objeto que definimos implica que nos esqueçamos momentaneamente da própria questão que nos levou a selecionar o documento. É preciso ouvi-lo, deixá-lo falar, dar-lhe a sua possibilidade de se mostrar tal como é. Não se pode saber antecipadamente tudo o que ele pode ter para nos dizer. Impor-lhe cedo demais um questionário estabelecido $a$ priori é o meio mais seguro de atrofiar e de deformar o seu testemunho. Utilizou-se muito a metáfora, renovada, de Bacon: "Submeter o documento à tortura, fazer com que ele vomite informações". Mas não, não o devemos violentar, porque o problema é apreender, em toda sua delicadeza e nos seus matizes, o exato alcance da significação dele. O melhor é não nos apressarmos. O historiador deve saber utilizar longas demoras (MARROU, 1974:93).

Um exemplo de "exacerbação do espírito crítico" bem ilustrado por Skinner são as fórmulas propostas por Sir Geoffrey Elton para o ofício do historiador. No empreendimento empirista de se tentar apreender os fatos do passado objetivamente, de se tentar alcançar a verdade e a verdadeira realidade do passado através de dados empíricos, revela-se um método totalmente dominado pela técnica e pela aplicação de princípios de crítica na busca por uma história "pura e dura” (Cf. SKINNER, 2005:11-38). Não há dúvidas de que tal método submeta os documentos "à tortura" com a intenção de se extrair a "verdade" do material, já que "o único objetivo do historiador é "contar a verdade acerca do passado"” (2005:18).

Essa postura diante dos documentos e materiais seria o equivalente a uma "atitude resmungona, minuciosa e intratável" com as testemunhas do passado, a que Marrou compara com a do mau policial ou investigador para quem qualquer pessoa chamada a depor é considerada culpada e suspeita até que apareça provas do contrário, porque além do "medo de ser enganado", existe a ideia bem arraigada de que as pessoas tentam sempre enganar (Cf. 1974:87-88). Costa aponta que essa atitude "dificulta muito a compreensão daquilo que está sendo estudado, quase inviabilizando entre nós a formação de bons historiadores” (2008:66).

É preciso que fique claro que a epokhé não supõe a ausência de uma abordagem crítica das fontes, o próprio Marrou traça um quadro geral para as fontes textuais que envolve crítica externa (crítica de autenticidade e crítica de proveniência) e crítica interna (crítica de interpretação e crítica de credibilidade), (1974:94-95). A epokhé implica que principalmente nas primeiras abordagens das fontes o historiador não vá armado com o questionário prévio para encontrar as tão esperadas respostas para sua pesquisa, pelo contrário, é necessário em algum nível colocar entre parênteses, suspender o juízo, pois "sair de nós mesmos significa estar disponíveis a ouvir com atenção o que os documentos históricos têm a nos revelar, que é o contrário de projetar sobre eles ideias ou teorias preestabelecidas" (FERNANDES, 1999).

\section{Filistorias}


Por fim, a suspensão do juízo implica também em história como curiosidade, curiosidade plena de valor existencial e cultural. O historiador é aquele que está disposto a gastar seu tempo escavando os escombros do passado (MARROU, 1974:231). Segundo Marrou, com a epokhé há uma suspensão das preocupações existenciais mais urgentes, uma saída do eu, expatriação, uma descoberta e consequente encontro do outro, assim, a história apresenta-se como "a descoberta de uma alteridade pura" (MARROU, 1974:226). Os estudantes de história estão o tempo todo em contato, em ganho de experiência e indo de encontro com homens de outros lugares, outras temporalidades e lógicas, homens que esperam para serem compreendidos por meio da simpatia, alteridade e abertura de espírito suficientes para tal empreendimento.

\section{Simpatia, alteridade e compreensão}

Simpatia e alteridade são duas faces da mesma moeda. Sem essa virtude que é a disposição de ir ao encontro do outro, a simpatia, não há alteridade. Para deixar nosso cenário um pouco mais complexo, Prost identifica a compreensão também como uma simpatia, um sentimento, "uma amizade" (2008:148). Ou seja, todas essas categorias e sentimentos interdependentes fazem parte de um mesmo processo cognitivo mais amplo, o da compreensão histórica (Verstehen). É, portanto, apropriado refleti-los em conjunto destacando suas potencialidades, possibilidades e limites.

Até aqui vimos que a simpatia é uma virtude do historiador que sabe "sair de si", mediante a epokhé, para ir de encontro ao outro (Cf. MARROU, 1974:87). Que essa virtude é o principal meio intuitivo de cognição e realiza uma identificação gradual entre a personalidade do historiador e o objeto estudado (Cf. TOPOLSKI, 1976:147), pois a simpatia é a "fonte e condição da compreensão" (MARROU, 1974:89). O conhecimento histórico possui uma especificidade, como pertencente ao quadro geral das ciências humanas, que é a necessidade de uma "sensibilidade por simpatia" (GADAMER, 1998:24). Marrou propõe ainda um aprofundamento da simpatia que resulta em história como amizade:

Se a compreensão é efetivamente essa dialética do $E u$ com o Outro que descrevemos, supõe a existência de uma larga base de comunhão fraternal entre sujeito e objeto, entre historiador e documento (para sermos mais precisos: e o homem que se revela através do documento, esse sinal). Como compreender, sem essa disposição de espírito que nos torna conaturais a

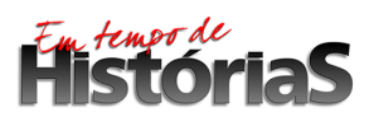

(PPGHIS/UnB) №. 31, Brasília, Ago - Dez 2017 ISSN 2316-1191 
outrem, que nos permite sentir as suas paixões, repensar as suas ideias à mesma luz a que ele as viu, numa palavra, comungar com o outro. O termo simpatia é mesmo insuficiente aqui: entre o historiador e o seu objeto é uma amizade que se deve estabelecer, se o historiador quer compreender, porque, segundo a bela fórmula de Santo Agostinho, "não se pode conhecer ninguém a não ser pela amizade", et nemo nisi per amicitiam cognoscitur (MARROU, 1974:88).

A simpatia que desagua em história como amizade e como escuta requer muita sensibilidade da parte do historiador. É o conjunto de virtudes que já se mostrou claro até aqui: disponibilidade, capacidade de escuta, cumplicidade com o outro, e na medida do possível "a disposição de entrar em sua personalidade, enxergar com seu olhar, sentir com sua sensibilidade, julgar de acordo com seus critérios" (PROST, 2008:147-148). De acordo com as propostas metodológicas de Marrou, o historiador não pode ser aquele homem que se fecha em suas questões e preocupações, não pode ser de espírito estreito. Voltamos consequentemente à necessidade de uma epokhé, pois o historiador "será aquele que aceitar pôr o seu pensamento em férias, empreender longos circuitos que o farão sair de seu meio, porque sabe que a dilação do eu proporciona esse rodeio que passa pela descoberta de outrem” (1974:80).

Pode-se recorrer a um exemplo tanto famoso quanto antigo de intensa simpatia e amizade para ilustrar essa comunhão e amor fraternal que deve se estabelecer entre o historiador, seus textos e objetos de estudo. O relato bíblico narra a amizade de Davi e Jônatas da seguinte maneira: "e sucedeu que, acabando ele de falar com Saul, a alma de Jônatas se apegou com a alma de Davi; e Jônatas o amou como à sua própria alma" (I Samuel 18.1). E depois de terem firmado um pacto de amizade: "Jônatas tirou o manto que vestia e o deu a Davi, e também lhe deu a sua roupa, a sua espada, o seu arco e o seu cinturão" (I Samuel 18.4). Um belo exemplo de compreensão, de colocar-se no lugar do outro, é o que o desenrolar da história de Davi e Jônatas nos conta. Assim, o exercício de reconstrução histórica, de compreensão e apreensão do passado não é sobretudo um ato de amor? (Cf. COSTA, 2008:64-67):

(...) a postura metodológica que deve estar presente no (bom) historiador quando de seu processo de reconstrução histórica: o amor. Enfatizo: o exercício de apreensão do passado, do passado que aconteceu, do passado registrado é como o próprio ato de educar, é um ato de amor, amor na plena acepção da palavra, um dar sem esperar nada em troca, um olhar para trás e desejar apenas entender o que aconteceu, participando de uma perspectiva comum com o texto estudado (COSTA, 2008:65).

\section{Filistorias}


O caso de Davi e Jônatas, que parece um tanto estranho para nós, pode ser um tipo e ilustração da "misteriosa comunicação entre as almas", como diz Gadamer. A comunhão fraternal da qual fala Marrou tem certamente seus limites e o historiador deve passar primeiro por um esforço de investigação hermenêutica para compreender textos por meio da apreensão de sentido, significado e perspectiva, por isso, o "compreender é o participar de uma perspectiva comum" (GADAMER, 1998:59). Gadamer argumenta que a compreensão de um texto "não nos coloca no lugar do outro, nem é o caso de pensar que se trata de penetrar a atividade espiritual do autor" (1998:59), mas o compartilhar de uma perspectiva comum já é em algum nível o tornar-se conatural ao outro.

A essa altura é importante indagar sobre quais são as consequências de toda essa alteridade que o historiador se expõe nesse processo de constituição do conhecimento histórico. A definição básica de alteridade, que já se esboçou até aqui, é "ser outro, colocar-se ou constituir-se como outro" (ABBAGNANO, 2007:34), mas o historiador só pode realizar tal empreendimento pelo pensamento em algum nível, por conta dos limites do próprio conhecimento histórico.

Uma das principais problemáticas que envolve a noção de alteridade é que "o outro é passível de alterar a vida psíquica do indivíduo e a apreensão que tem de si mesmo" (ANSARTDOURLEN, 2009:23). É interessante perceber que a noção geral de alteridade que se aplica ao relacionamento de indivíduos de um mesmo lugar e época, pode se aplicar também ao relacionamento entre o historiador e os homens do passado que se revelam através de suas fontes, afinal, a história "é um trabalho de auto-análise": "ao escrever história o historiador se cria a si mesmo" (PROST, 2008:91). Qualquer ofício singulariza e caracteriza aquele que o exerce, a história como ofício também modela a personalidade do historiador (Cf. PROST, 2000:17). Modela através das experiências adquiridas pela imaginação e pensamento no estudo dos homens do passado, e ao remeter o historiador para a "historicidade da condição humana", o faz encontrar sua própria historicidade (Cf. PROST, 2000:19).

Só aqui apresento o caráter provisório e relativo da epokhé, pois as preocupações existenciais do historiador podem ser abafadas, mas nunca eliminadas (MARROU, 1974:199). Até porque por mais que se simpatize e se disponha a essa alteridade pelo pensamento é certo que "o historiador não deixará de ser ele mesmo; nunca chegará a tornar-se outro, seja qual for o esforço de compreensão que possa fazer” (PROST, 2008:150). Além de impraticável e impossível, tornar-se o outro não seria interessante e produtivo ao historiador, pois alteridade e

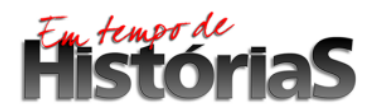


compreensão, bases do conhecimento histórico, apenas são necessárias se existe o outro, o diferente. Fazendo contraponto a Dilthey, cuja concepção de história se dá a partir do conhecimento do $\mathrm{Eu}$, Marrou destaca que o conhecimento histórico se origina dessa dialética entre o Eu e o Outro (1974:226). Para Marrou, é o historiador que constrói a cognição histórica a partir de sua qualidade e abertura de espírito para com esse outro (Cf. TOPOLSKI, 1976:147).

Para além de ser o conhecimento do outro, história também é autoconhecimento. Não é apenas conhecimento do passado, mas “conhecimento do passado no presente". História é "o re-pensamento, a re-ativação, a re-ação no presente, pelo historiador, de coisas que, outrora, haviam sido pensadas, experimentadas e praticadas por outras pessoas" (PROST, 2008:150). Nesse sentido, quanto mais compreende as experiências sociais e a vida em sociedade, mais o historiador será sensível a perceber as nuances do passado. Para compreender, o historiador utiliza o raciocínio por analogia ou um "raciocínio natural", que consiste em relatar o passado em analogia com o presente transferindo "modos de explicação comprovados pela experiência social cotidiana do homem comum" (PROST, 2008:145).

A compreensão por meio de um conhecimento de tipo analógico somente é possível através de elementos de natureza universal ou geral. Um documento histórico pode ser original, mas sempre será semelhante e análogo a outros, só assim ele pode ser acessado e conhecido (Cf. MARROU, 1974:100). Um exemplo interessante é a decifração do egípcio faraônico e da pedra de roseta por Champollion, ele foi capaz de tal feito porque conhecia o copta, língua com elementos análogos aos hieróglifos. Por outro lado, um sistema como o quippu peruano, por ser tão diferente, ainda resiste às tentativas de interpretação e compreensão (Cf. MARROU, 1974:100). Da mesma forma, apenas se pode compreender os homens do passado pelas semelhanças, a começar pelas línguas, conosco:

Só compreendemos o outro pelas suas parecenças comigo, com a minha experiência adquirida, com o meu próprio clima ou o universo mental. Só podemos compreender aquilo que, em grande medida, já é nosso, fraterno; se o outro fosse completamente dissemelhante, estranho cem por cento, não se vê como a sua compreensão seria possível (MARROU, 1974:79).

Assim sendo, os homens do passado que se revelam através dos documentos e dos vestígios que deixaram, possuem a curiosa capacidade de ser ao mesmo tempo diferentes e semelhantes a nós. Parece óbvio tal afirmação, mas temos a tendência, principalmente aqueles que não têm um contato mais intenso com os estudos históricos, ou de achar que esses homens

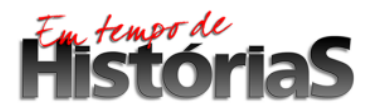


são completamente estranhos, negando-lhes até mesmo uma dimensão mais humana, ou de atribuir-lhes categorias que são nossas, incorrendo em anacronismos grosseiros. É importante reconhecer uma continuidade entre os homens no tempo e um movimento de vaivém entre passado e presente, o que demonstra mais ainda o vínculo entre compreensão e experiência vivida (PROST, 2008:145).

Dadas as potencialidades da compreensão histórica, é preciso destacar algumas de suas limitações que advêm da própria natureza do conhecimento histórico. O primeiro problema são os limites morais da compreensão. Compreender é também de alguma forma quase que justificar, entender as motivações e razões, e há uma série de momentos e personagens obscuros na nossa história que apontam para uma impossibilidade moral e ética. "Colocar-se no lugar", ou mesmo compartilhar de uma perspectiva comum, de Hitler, por exemplo, não é tarefa para o historiador (PROST, 2008:148-149). Existem grupos que infelizmente ainda hoje a executa muito bem. Os neonazistas compreendem Hitler tão bem a ponto de não só tornarem-se conaturais a ele, mas também de odiar tudo o que ele odiava.

A segunda problemática envolve a questão da objetividade e da imparcialidade. $\mathrm{O}$ historiador não pode procurar compreender apenas uma das partes de seu objeto de análise, mas deve ter a lucidez necessária para compreender o conjunto das partes e situações afim de dar mais valor à sua representação e análise (Cf. PROST, 2008:149). Tal aspecto pode ser mais difícil para o historiador que é engajado por uma causa ou luta política. É claro que sua obra mostrará seus compromissos, porém, no processo da compreensão e escrita de sua obra, quer artigo ou livro, o historiador não pode simplesmente ocultar ou omitir fatos, documentos, evidências que provam o contrário, ação que pode alterar a percepção de seus leitores sobre determinado acontecimento, personagem ou período histórico (Cf. COSTA, 2004:56).

Por fim, o problema da legitimidade da transposição. A compreensão é de certa forma precária pois não se tem uma garantia da operação e a certeza de que realmente se compreendeu, por razão da distância no tempo, o historiador sempre vai lidar com o risco do equívoco (Cf. PROST, 2008:149). A legitimidade da transposição ainda impõe muitos desafios ao historiador. Espera-se que o mesmo procure apreender e compreender a complexidade do real, mas é aí que se esbarra em certos conceitos e categorias como a burguesia capitalista, o homem medieval, o feudalismo, que tendem a suprimir os homens, "o ser humano cuja individualidade é o único organismo verdadeiro autenticamente fornecido pela experiência" (MARROU, 1974:162). Os

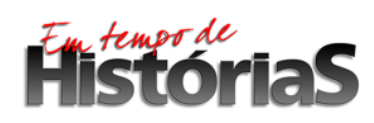


fatos humanos e a realidade histórica são tão ricos e complexos em sua natureza que o esforço de compreensão e descoberta é inesgotável (MARROU, 1974:172).

Simpatia e alteridade certamente são um bom caminho metodológico para qualquer tipo de abordagem das fontes e para o alcance da compreensão, mas é preciso discernimento e senso crítico para perceber os reais desafios que os limites do conhecimento histórico nos impõem.

\section{Considerações finais: Narciso e Ulisses em Ítaca, dois conselhos ao (aprendiz de) historiador}

Em sua Metamorfoses (MORE, 1922), o poeta romano Ovídio (43 a.C. - 18 d.C.) nos conta o mito do semideus Narciso. Inigualável em beleza, sua mãe, a ninfa Liríope, que o concebeu do deus do rio Cefiso, queria saber se o filho alcançaria uma idade avançada. Implorando ao oráculo Tirésias por uma profecia que lhe revelasse uma resposta para essa indagação, o oráculo respondeu: "Se ele não conhecer a si mesmo, terá uma longa vida debaixo do sol" (Metamorfoses, III, 337-348).

As palavras do oráculo pareceram triviais, mas transformaram-se em uma fatalidade para Narciso. O rapaz era amado por muitos por causa de sua beleza, mas o orgulho era tamanho que não deixava conquistar-se por ninguém. Mulheres, homens e até mesmo ninfas se apaixonavam por Narciso, entre elas a ninfa Eco, que havia sido punida por Juno (Hera) para que ao falar só conseguisse repetir a última palavra do discurso de outros, pois ela havia enganado a deusa com contos intermináveis enquanto Júpiter (Zeus) escapava de ser pego passeando nos bosques com as ninfas (Metamorfoses, III, 350-370). Certo dia, Eco viu Narciso divagando pela floresta e seguindo-o o amou intensamente, mas como só podia repetir as últimas palavras do que Narciso dizia, o que recebeu foi incompreensão. Enquanto Narciso perguntava “quem está aqui!?”, Eco replicava “aqui!” e assim por diante. Já desesperada pela impossibilidade de se fazer entender, Eco aparece e o abraça, no que Narciso corre e a nega dizendo: “Tire suas mãos de mim! Prefiro morrer do que entregar-me a ti!" e Eco responde arrasada: “entregar-me a ti!” (Metamorfoses, III, 370-392).

Tomada pela tristeza da rejeição, Eco esconde-se nas profundas florestas e em cavernas solitárias das montanhas. Porém, sua prece aos deuses para que se Narciso amasse que lhe fosse negado o que ama, foi atendida por Nêmesis, que o castigou. Um dia, já cansado depois de caçar, Narciso encontrou uma fonte de água límpida, e a sede por água não foi a única sede que

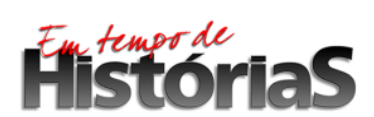


ele viu crescer na ocasião. Narciso apaixonou-se pela própria imagem tão bela e inalcançável refletida na fonte, como num espelho. Cansado de tentar abraçar e beijar o objeto da paixão que nunca se deixava possuir, percebeu que se tratava dele mesmo: "este sou eu!" (Metamorfoses, III, 392-463), e, exausto, morreu.

O mito de Narciso ilustra a tomada de consciência da individualidade, consciência de si, e a relaciona com uma máxima filosófica, a do "conhecer a si mesmo" (SPINELLI, 2010:195). Três momentos principais podem ser identificados no mito, o da recusa a Eco, que no contexto desta conclusão chamo de recusa à alteridade. Narciso não quis perder sua individualidade, não quis se entregar a Eco e perder a posse de si mesmo. O castigo e, por fim, a descoberta de si mesmo, que representa o "drama da individualidade". Ao olhar o "Narciso" de Caravaggio (1571 - 1610 d.C.), o observador tende a colocar-se no lugar de Narciso, pois “o drama de Narciso é o mesmo de todos nós” (SPINELLI, 2010:196-198).

Mas, afinal, no que o mito de Narciso contribui para delinear características essenciais e básicas da personalidade e do ofício de historiador? Todos temos um Narciso dentro de nós, nos resta saber controlá-lo. Vimos que mesmo a suspensão do juízo (epokhé) tem um caráter provisório e relativo porque o historiador não pode eliminar suas preocupações existenciais, apenas abafá-las. Mas é abafando essas preocupações, tentando esquecer por um momento o que se é, que o historiador pode se permitir uma maior abertura de espírito para com suas fontes e os homens do passado (MARROU, 1974:80, 199 e 226).

O primeiro conselho metodológico é a prática da abertura de espírito. Em "tempos de indiferença e desengajamentos (com os outros e consigo mesmo)" (SEIXAS, 2009:64), o historiador não pode dar-se à recusa da alteridade, não pode ser como Narciso centrado em si mesmo, mas justamente o contrário disso, começando por abrir-se a seus contemporâneos, sua própria sociedade e depois em direção ao passado. Tal postura deve fazer parte também de um compromisso moral e ético, pois a desvalorização do sentimento de alteridade é resultado de uma lógica de exclusão, que nos regimes totalitários do século XX manifestou-se de forma desastrosa (ANSART-DOURLEN, 2009:26).

É preciso ouvir atentamente as palavras de exortação de Marrou: “O historiador deve ser também, e primeiro que tudo, um homem plenamente homem, aberto a tudo que é humano, em vez de aparecer atrofiado como um rato de biblioteca e um ficheiro!” (1974:93). É interessante a criativa comparação de Bloch: "o bom historiador se parece com o ogro da lenda. Onde fareja carne humana, sabe que ali está a sua caça" (2001:54).

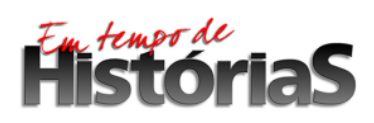

(PPGHIS/UnB) №. 31, Brasília, Ago - Dez 2017 ISSN 2316-1191 
Constatamos que existe um forte vínculo entre compreensão e experiência vivida, que a compreensão se dar a partir de um raciocínio por analogia, então, nada melhor para se fazer boa história do que uma ampliação do campo de experiência do historiador, ele deve exercitar sua compreensão a partir de uma abertura para a vida em sociedade, pois "o historiador compreende as situações históricas a partir da experiência adquirida das diversas práticas sociais" (PROST, 2008:145). O historiador é um coletor de experiências, tanto do presente como do passado. Depois de citar uma longa lista de experiências adquiridas pelo estudo da história, Prost declara: "Eu tive, assim, a chance, graças a história, de viver muitas vidas, e de ter uma experiência multiforme. Eu frequentei os homens os mais diversos, e vivi, com eles, as situações mais variadas. Na imaginação, é verdade, e em pensamento" (2000:18).

Essas experiências que o historiador coleta dos outros, quer do passado ou do presente, acabam por moldar sua personalidade. Não dá para fugir como Narciso, a boa notícia é que não dá para fazer história sem uma entrega mínima, o historiador acaba descobrindo o homem que ele é (e conhecendo a si mesmo!), pois a história lhe mostra sua própria historicidade: “capturado pela história, definido por ela, ele não pode escapar-lhe” (PROST, 2000:19).

O segundo conselho metodológico é o amor e a paixão: "para o homem, enquanto homem, nada tem valor a menos que ele possa fazê-lo com paixão" (WEBER, 2000:27). Para o entendimento de onde quero chegar com este conselho, contarei outra história. Desta vez o herói é Ulisses, o protagonista da Odisséia de Homero (MURRAY, 1919). Depois dos acontecimentos da Guerra de Tróia, tudo que Ulisses mais deseja é voltar para casa, para junto de sua mulher Penélope e seu filho Telémaco, recém-nascido quando partira. Todos os deuses determinaram que ele deveria retornar para Ítaca, exceto Poseidon, que continuou a lhe infligir provações (Odisséia, I. 1-25).

Em sua trajetória de volta para casa Ulisses naufragou na ilha Ogígia, onde a deusa Calipso, filha de Atlas, era rainha. Apaixonada pelo herói, não só o recepcionou muito bem, mas também lhe prometeu imortalidade e juventude se ali ficasse com ela. Apesar de toda a beleza de Calipso, da ilha, do sabor da comida, Ulisses se sentia profundamente infeliz e vazio, pois onde realmente queria estar era ao lado da mulher e filho, em Ítaca. Prisioneiro de Calipso, só conseguiu sua liberdade de volta pela intercessão que Atena fez a Zeus, o qual enviou um recado através de Hermes para que a deusa deixasse Ulisses partir (Odisséia, I. 44-79 e VII. 240-270). 
O que Ulisses tem a ensinar ao historiador? Esta parte de sua história significa que "para o pensamento mitológico - e posteriormente filosófico - grego, uma vida boa, ainda que finita, supera, e muito, uma vida eterna, fora de lugar" (FILHO; MEUCCI, 2012:32). Acontece que na escolha do tema, o qual o historiador passará quase sempre anos a fio pesquisando, e posteriormente, no desenvolvimento do trabalho, é necessário amor, uma paixão racional, envolvimento (Cf. COSTA, 2004:54). Nada melhor do que estudar o que se ama, o que se quer, estar no lugar certo, como Ulisses em Ítaca, para praticar a simpatia e alteridade. Essa simpatia, condição da compreensão, identificação gradual entre a personalidade do historiador e seu tema, a aceitação da alteridade, capacidade de abrir-se ao outro, exige uma boa dose de amor e de paixão. Paixão, contudo, racional, principalmente quando o historiador está envolvido em compromissos políticos ou religiosos mais definidos, pois uma paixão obcecada corre o risco de naturalizar fatos, de ser parcial (PROST, 2008:89), ou ainda mais grave, mesmo de omitir dados das fontes.

Numa perspectiva filosófica, pode-se afirmar que "Do conhecimento histórico" de Marrou contém não só as diversas correntes filosóficas explicitadas inicialmente, mas também há um humanismo cristão (PROST, 2008:148) que se manifesta fortemente em sua obra. Há um peso do humanismo cristão na elaboração das categorias de epokhé, simpatia e alteridade por Marrou. Enquanto Narciso ama a si mesmo em si mesmo, Jesus Cristo declarando a máxima "ame ao próximo como a ti mesmo", foi o primeiro que "reconheceu no amor de si mesmo a gratuidade e a pureza intencional do amor" (SPINELLI, 2010:199). Nesse princípio cristão há uma antecedência do eu em relação ao outro. A novidade é que é um princípio relacional que envolve a inclusão do outro, mas onde ainda assim há a possibilidade do outro se tornar o inimigo quando não há amor (SPINELLI, 2010:199).

É papel do historiador, portanto, compreender os ecos do passado, inclusive aqueles que colocam suas crenças e ideologias pessoais em xeque, e não os recusar como se estivesse atormentado por eles, como um Narciso que foge de Eco. É preciso tentar compreender, mesmo quando os homens do passado só repetem de volta as últimas palavras, o que às vezes parece gerar incompreensão. Tal postura só é possível através da epokhé, da simpatia e da não recusa à alteridade, que desenvolve no historiador mais capacidade de escuta, de cumplicidade e abertura com o outro, qualidades essenciais para a construção do conhecimento histórico. 


\section{Referências Bibliográficas}

ABBAGNANO, Nicola. Epoché. In: Dicionário de Filosofia. São Paulo: Martins Fontes, 2007.

Alteridade. In: Dicionário de Filosofia. São Paulo: Martins Fontes, 2007.

ANSART-DOURLEN, Michèle. A noção de alteridade. Do sujeito segundo a razão iluminista à crise de identidade no mundo contemporâneo. In: NAXARA, Márcia; MARSON, Izabel; BREPOHL, Marion (org.). Figurações do outro. Uberlândia: EDUFU, 2009.

BÍBLIA. Bíblia Sagrada. Tradução de João Ferreira de Almeida. Sociedade Bíblica do Brasil, 1995.

Bíblia de Jerusalém. Paulus: São Paulo, 2002.

BLOCH, Marc. Apologia da história ou o ofício de historiador. Rio de Janeiro: Zahar, 2001.

COSTA, Ricardo da. Para que serve a História? Para nada... In: SINAIS - Revista eletrônica. Ciências Sociais. Vitória: CCHN, UFES, Edição n.03, v.1, 2008.

. O conhecimento histórico e a compreensão do passado: o historiador e a arqueologia das palavras. In: ZIERER, Adriana (coord.). Revista Outros Tempos, São Luís: UEMA, volume 1, 2004.

FERNANDES, Raúl Cesar Gouveia. Reflexões sobre o estudo da Idade Média. In: Revista VIDETUR. n.6. São Paulo: Editora Mandruvá, 1999.

FILHO, Clóvis de Barros; MEUCCI, Arthur. A vida que vale a pena ser vivida. Rio de Janeiro: Vozes, 2012.

GADAMER, Hans-Georg. O problema da consciência histórica. Rio de Janeiro: Editora Fundação Getúlio Vargas, 1998.

HOMERO. The Odyssey with an English Translation by A.T. Murray, in two volumes. Cambridge, MA; London: Harvard University Press, 1919.

LENNON, Thomas M. Descartes, Arcesilau e a estrutura da epokhé. Educação e Filosofia, Uberlândia,v. 25, n. Especial, p. 37-62, 2011.

LÉVI-STRAUSS, Claude. História y Etnología. In: Antropología Estructural. Barcelona/Buenos Aires: Ediciones Paidós, 1995.

MARCONDES, Danilo. Iniciação à História da Filosofia. Dos pré-socráticos à Wittgenstein. Rio de Janeiro: Jorge Zahar Ed., 2001.

MARROU, Henri-Irénée. Do conhecimento histórico. Lisboa: Editoral Aster, 1974.

De la connaissance historique. Paris: Éditions du Seuil, 1954.

OVÍDIO. Metamorphoses. Brookes More (trad.). Boston: Cornhill Publishing Co., 1922.

PROST, Antoine. Doze lições sobre a História. Belo Horizonte: Autêntica Editora, 2008.

. Como a História faz o historiador? Anos 90, Porto Alegre, n.14, 2000.

RODRIGUES, Henrique Estrada. Lévi-Strauss, Braudel e o tempo dos historiadores. Revista Brasileira de História. São Paulo, v.29, nº 57, pp.165-186, 2009.

SEIXAS, Jacy Alves. A imaginação do outro e as subjetividades narcísicas. Um olhar sobre a in-visibilidade contemporânea [o mal-estar de Flaubert no orkut]. In: NAXARA, Márcia; MARSON, Izabel; BREPOHL, Marion (org.). Figurações do outro. Uberlândia: EDUFU, 2009.

SKINNER, Quentin. A prática da história e o culto do facto. In: SKINNER, Quentin. Visões da política: sobre os métodos históricos. Algés: Difel, 2005.

SPINELLI, Miguel. De Narciso a Epicuro: Do emergir ao resgate da individualidade. Hypnos, São Paulo, n.25, pp.194-210, 2010.

TOPOLSKI, Jerzy. Methodology of History. Holland: Dordrecht, D. Reidel, 1976.

WEBER, Max. Ciência e Política: duas vocações. São Paulo: Cultrix, 2000.

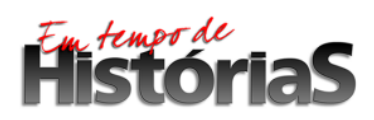

(PPGHIS/UnB) №. 31, Brasília, Ago - Dez 2017 ISSN 2316-1191 